Paidéia, 2005, 15(31), 195-205

\title{
RELEITURAS DA INDIFERENÇA: UM ESTUDO BASEADO EM CARTAS DE JESUÍTAS DOS SÉCULOS XVI E XVII ${ }^{1}$
}

\author{
Mariana Leal de Barros \\ Marina Massimi \\ FFCLRP - Universidade de São Paulo
}

\begin{abstract}
Resumo: Este estudo compreende o conceito de indiferença, questão analisada a partir das Litterae Indipetae, cartas em que jesuítas dos séculos XVI e XVII pediam à Companhia de Jesus para servirem nas Missões. O documento revela a particularidade de cada relato, principalmente devido às justificativas do desejo de servir no além-mar, configurando sua riqueza do ponto de vista psicológico, religioso e social. A análise do conteúdo foi baseada na contextualização dos documentos, destacando a compreensão da estrutura formal das cartas, da retórica da época, assim como da base filosófica da Ordem e das regras que a caracterizam. O objetivo funda-se no estudo de cartas em que jesuítas declaram-se indiferentes frente à escolha do lugar a servir. Verifica-se então, que a indiferença é um conceito próprio da espiritualidade jesuítica sendo importante para a compreensão da psicologia da época, pois se associa ainda às idéias de coragem, deliberação do desejo e meio-termo.
\end{abstract}

Palavras-chave: Jesuíta; Companhia de Jesus; Litterae Indipetae; Indiferença.

\section{ANALYSIS OF INDIFFERENCE: A STUDY BASED ON JESUIT LETTERS IN 16TH AND 17TH CENTURY}

\begin{abstract}
This study comprehend the conceit of indifference, what is analyzed in the Litterae Indipetae, letters that jesuits have asked to the Jesus Company to go to the Mission, in the centuries XVI and XVII. The document show the particularity from each $t$ account specially because of the explanation about the desire of to serve overseas, what configure the wealth on the point of view by the psychological, religious and social. The content analysis was based on the the documents context, with an emphasis on the formal letters structure undertanding, the rhetoric of this period, and the philosophical base of the Company and the rules that characterize her. The objective is based on the study of the letters, which the jesuits set themselves indifferent about the place that, they could to serve. So, it was observed that the indifference is a concept own of the jesuit's spirituality and it's important to understand the psicology in this epoch, because still is associate with the ideas of courage, deliberation about the desire and middle- term.
\end{abstract}

Key-words: Jesuit; Jesus Company; Littearae Indipetae; Indifference.

Introdução: As contribuições dos jesuítas foram pesquisadas nos diversos domínios da religião, sociedade, cultura, ciência, arte e da política, devido à grande importância que os missionários tiveram no passado e à influência que trouxeram para o presente ${ }^{1}$.

\footnotetext{
${ }^{1}$ Recebido para publicação em 22/02/2005 e aceito em 11/10/2005. ${ }^{2}$ Endereço para correspondência: Marina Massimi, Faculdade de Filosofia, Ciências e Letras de Ribeirão Preto da Universidade de São Paulo - Departamento de Psicologia e Educação, Avenida Bandeirantes, 3900, Ribeirão Preto - SP, CEP: 14040-901, E-mail: mmassimi@ffclrp.usp.br
}

A partir da criação da Companhia de Jesus no início do século XVI, fundada por Inácio de Loyola, os jesuítas foram protagonistas de uma significativa presença cultural e social, em vários países do Oriente e Ocidente (Lacouture, 1994). A participação destes missionários na elaboração do saber e da ciência a partir deste período é hoje apontada por estudiosos

\footnotetext{
${ }^{1}$ Andrade (1981), Baldini (1992), Barreto (1983), Caeiro (1982), Caeiro (1989), Giard (1995), Giard e Vaucelles (1996), Maravall (1997), Martins (1989), Rodrigues (1985).
} 
da história da ciência e da cultura, mas passou por períodos de esquecimento. Até recentemente, historiadores não jesuítas, mostravam pouco interesse na pesquisa da história dos missionários da Companhia de Jesus. Nos últimos cinqüenta anos, um grande número de estudos evidencia uma mudança de perspectiva, que brota da superação de antigos pressupostos da interpretação da historiografia que retratava os jesuítas, ora como santos, ora como demônios (O’ Malley, 1993) ${ }^{2}$.

No século XVI, os pensadores da Companhia, visando realizar uma síntese entre a herança do catolicismo medieval e o novo espírito renascentista, encarregam-se de "traduzir" tais concepções num método de formação do homem, seja em seu percurso evolutivo da infância até à maturidade pela educação, seja no que diz respeito à aculturação dos povos ameríndios, africanos e orientais, através do processo de cristianização. Nesse âmbito, o conhecimento da subjetividade, por um lado, e da dinâmica das relações sociais, por outro, aparecem como instrumentos necessários e, num certo sentido, privilegiados. Disto brota o interesse pelos processos psíquicos que, porém, não são concebidos de forma autônoma, mas integrados à experiência humana em sua totalidade corporal, anímica e espiritual. O modelo para compreensão desta Antropologia para a formação do indivíduo é fornecido pelos Exercícios Espirituais de Inácio de Loyola (Massimi, 1999).

Nessa perspectiva, como seria olhar para estes missionários do ponto de vista de sua experiência humana? Esse trabalho busca compreender a experiência de jovens jesuítas dos séculos XVI e XVII, tal como eles a percebiam, para poder abordar o processo de construção do saber sobre si mesmos a partir de alicerces teóricos e metodológicos fundamentais, assimilados no período de sua formação na Companhia (Massimi, 1999). Felizmente a investigação histórica neste domínio é facilitada pelo cuidado com a preservação da memória e das fontes históricas,

\footnotetext{
2 “As renovações da história religiosa não significam uma recrudescência do cristianismo, mas a diluição de suas instituições e de doutrinas nas novas estruturas da nação, sua passagem de estado de corpo opaco e resistente a um de transparência e movimento. Os preconceitos da história desaparecem quando se modifica a situação a que se referem. A organização viva de uma sociedade, investida na ótica de seus historiadores, se transforma, então, num passado suscetível de ser estudado” (De Certeau 2002, p. 44).
}

uma característica própria da Companhia ao longo do tempo, fator que possibilita aos pesquisadores entrar em contato com uma documentação vastíssima, de conteúdos ricos quanto à contribuição para a história cultural.

Dentre esta documentação, destaca-se a correspondência epistolar. Longo (1981), em seu estudo sobre a retórica e a ars dictandi (arte de escrever cartas), chama a atenção para os séculos XVI e $\mathrm{XVII}^{3}$, época em que a carta é encarada não só como agente da comunicação, mas também, como gênero literário em que o autor é personagem do conteúdo, ou seja, espaço para colocar questões pessoais, contendo teorias e ideais, possibilitando ainda elaboração de experiências (O’Malley, 1999). A partir do exemplo de Santo Inácio de Loyola, que utilizava a carta como instrumento de propagação de seus ensinamentos $^{4}$, ela se torna recurso fundamental para promover a comunicação entre os membros da Companhia (O’ Malley, 1993); em uma destinada ao Padre Pedro Fabro na Alemanha, Inácio recomenda que a sua escrita seja regrada para poder ser utilizada conforme os objetivos próprios: "Peço que em nossa correspondência procedamos para o maior serviço de sua divina bondade e maior proveito do próximo" (p.27). Existe, pois, uma repreensão à maneira desordenada de escrever. A carta principal - destinada a ser de domínio público - "a qual se pudesse mostrar a qualquer pessoa” (p.28) deve constituir um relato da atividade missionária de quem escreve, para que "possa servir para a maior edificação dos ouvintes ou leitores". Inácio recomenda que "não se misture matéria que não vem ao caso", a qual deve ser colocada "em folhas separadas". Para que a escrita da carta seja ordenada, ele recomenda escrevê-la duas vezes "torneis a escrevê-la ou a façais escrever depois de corrigida”(p.28).

Desse modo, a correspondência epistolar produzia no âmbito da Companhia é orientada por normas precisas contidas nas Constituições, sendo que são previstas diferenças nas modalidades de escre-

\footnotetext{
${ }^{3}$ Longo (1981) acrescenta que este período é interessante por coincidir com o advento da impressão com caracteres móveis e a afirmação das publicações de epistolares privados, o que permitiu a produção de grande quantidade de material documental.

${ }^{4}$ Como se pode encontrar na seleção Cartas (1993), de Inácio de Loyola.
} 
ver a carta devido à diversidade de objetivos e destinatários (Pecora, 1999). Em primeiro lugar, as cartas promovem a edificação espiritual da Companhia, como consta na terceira parte das Constituições, dedicada à "conservação da alma e ao progresso nas virtudes", em que se recomenda a "leitura de cartas edificantes” (p.103). Da mesma forma, recomendase a prática da correspondência epistolar voltada à edificação e construção da comunidade, no capítulo primeiro da oitava parte principal (p.675). Em segundo lugar, as cartas são um meio de comunicação e troca de informações entre os "sócios" e os superiores da Ordem, conforme se afirma na quarta parte do mesmo texto, no capítulo décimo sétimo, em que se coloca a necessidade de que os responsáveis pela formação dos estudantes escrevam cada ano ao Padre Geral e duas vezes por ano ao Provincial, recomendando que "as cartas enviem-se fechadas, de modo a ninguém saber o que o outro escreve” (p.159). Em terceiro lugar, as cartas servem para manter unidade entre a cabeça do Corpo da Companhia e os membros em missão, devendo ser a comunicação epistolar recíproca e detalhada. Nesta mesma perspectiva, elas se tornam um meio eficaz de governo da Companhia, para que o Padre Geral possa manter a observância das Constituições, e ele se serve do auxílio de um secretário para poder realizar a tarefa da escrita.

Nesse contexto surgem as Litterae Indipetae, que são documentos de inegável valor histórico, e ricos quanto ao teor subjetivo de seus conteúdos, capazes de refletir a interioridade de um corpo social que não se restringe à Companhia de Jesus, cuja análise pode abarcar amplamente o imaginário da época de que tratam. As cartas Indipetae representam um detalhe $^{5}$ que espelha vivências de épocas distantes com sabor ainda fresco, permitindo que se ouse aproximar para conhecer a experiência dos jovens daquela época (Roscioni, 2001).

\section{As Indipetae}

As Indipetae ${ }^{6}$ são cartas datadas dos séculos XVI e XVII, através das quais os jesuítas pediam permissão à Companhia de Jesus para servirem nas

\footnotetext{
5 "Cada historiador permanece um poeta do detalhe e brinca sem cessar, como o esteta, com as mil harmonias que uma peça rara desperta numa rede de conhecimentos” (De Certeau, 2002, p. 88). ${ }^{6}$ Indipetae - Pedido às Índias.
}

Missões. O material pertence ao Arquivo da Cúria Geral de Roma, onde foram feitas cópias de 118 delas, após um levantamento que considerou aspectos que configurariam uma homogeneidade, que facilitaria a feitura da análise (idade, colégio de origem e língua dos seus autores).

Os documentos eram todos redigidos por jovens entre dezessete e trinta anos, pertencentes a colégios italianos, espanhóis e portugueses da Companhia de Jesus, e destinados ao Padre Geral da Companhia, que deliberaria a respeito da concessão. Desta maneira, eles escreviam nas cartas justificativas para que seu pedido fosse aceito, o que incluía a descrição das próprias características pessoais (físicas e psicológicas), de modo que pudessem ser avaliado se atendiam às exigências da própria Companhia de Jesus.

\section{Uma aproximação às cartas}

Para análise do conteúdo das cartas, foi necessária a leitura dos documentos à luz do contexto cultural em que foram redigidos, evidenciando a influência do espírito renascentista da época e a contribuição da doutrina aristotélico-tomista ${ }^{7}$, que configurou a base filosófica da criação e organização da Companhia de Jesus, inclusive no que diz respeito aos conhecimentos psicológicos. Neste sentido, vale à pena destacar importância dos Conimbricenses, instrumentos didáticos, elaborados em Coimbra, constituídos por tratados que comentam as obras aristotélicas e utilizados na formação dos jesuítas; procurou-se apreender as categorias utilizadas pelos autores das cartas Indipetae para o entendimento de suas vivências, de acordo como foram nelas elaboradas.

Outro ponto necessário a ser ressaltado para a contextualização dos documentos, foi a compreensão das regras que caracterizam a Ordem dos Jesuítas, definidas nas Constituições ${ }^{8}$, e de seus modelos de imitação e inspiração, como Santo Inácio de Loyola e S. Francisco Xavier, somando-se à leitura de suas obras, em especial dos Exercícios Espirituais

\footnotetext{
${ }^{7}$ A filosofia aristotélica possui fundamental importância na construção da Companhia de Jesus também pelo fato de ter sido retomada e interpretada por São Tomás de Aquino, na Suma Teológica vol.III (1980).

${ }^{8}$ Trata-se de um compêndio das regras jesuíticas, cujo objetivo era auxiliar no trabalho de regrar a vida e contribuir para seu crescimento espiritual.
} 
$\left(\mathrm{O}^{\prime}\right.$ Malley, 1999) ${ }^{9}$. Além disso, realizou-se o estudo da estrutura formal das cartas e do modelo retórico exigido - ou intencionado - na época, dentro da Companhia.

\section{Como as cartas se revelam}

As Indipetae despertam, para quem delas se aproxima, questões instigantes quanto à compreensão da experiência individual relatada nos documentos: para além dos modelos e das normas da retórica e da correspondência epistolar, o material revela a particularidade de cada relato que, ao justificar o desejo da missão de além-mar, apresenta conteúdos ricos do ponto de vista psicológico, religioso e social.

Junto à expressão do desejo de serem missionários os jesuítas poderiam indicar o lugar em que gostariam de servir ${ }^{10}$, mas muitos se colocavam indiferentes quanto a essa escolha, em posição de total disponibilidade. Neste sentido, surge o objetivo de conhecer nas cartas o que movia esses jovens a se doarem integralmente às Missões, indepedente do lugar para o qual poderiam ser enviados e levando em conta o sentido próprio que a idéia de indiferença assume no contexto da espiritualidade jesuítica. Esta questão, fundamentada numa característica recorrente das cartas Indipetae, levou ainda à compreensão de conceitos que se percebe estarem relacionados à condição de indiferença: deliberação do desejo, obediência, coragem, meio-termo e liberdade.

\section{O caminho do além mar}

A aventura das Grandes Navegações e dos descobrimentos geográficos faziam com que a concepção de mundo fosse revista. A leitura e compreensão das cartas Indipetae revela que, para seus autores, o além-mar era inédito e temível, ao mesmo tempo, que fantástico. O inusitado permeava a experiência dos missionários jesuítas, que aprendiam sobre o Novo Mundo em seus colégios, através das cartas, relatos e biografias que lhes preenchiam a imaginação. A experiência missionária era divulgada, de forma a transmitir informações sobre o dia - a -

\footnotetext{
${ }^{9}$ Inácio utilizou os Exercícios como instrumento fundamental para a formação dos membros da Companhia, daí a importância deste texto como referência (O’Malley, 1999).

${ }^{10}$ Era comum os jesuítas pedirem para serem enviados tanto para Ocidente (Peru, México e Brasil), quanto para o Oriente ( Japão, China e Índia).
}

dia, sobre o lugar onde estavam, mas havia inclusive relatos íntimos, acerca de sentimentos de solidão, esperanças e temores, que eram comunicados aos companheiros distantes e que suscitavam tanto medos e desistências, quanto eram capazes de motivar os candidatos às Missões, ainda que considerando as dificuldades descritas pelos relatos dos missionários veteranos. Isto pode ser percebido em várias cartas analisadas, assim como nos trechos selecionados:

\begin{abstract}
"Abra dos años poco mas, o menos; que leyendo, $y$ mirando con mas attention, que otras veçes solia, lo que nuestros padres hacen en las Indias orientales, specialmente en el Japon; y los travajos, que pasan por Christo Nuestro Señor en la conversion de las animas; sentia em mi grandes deseos de imitarles en lo que tanto Nuestro Señor se sirve” (Balthasar de Torres, 1584, carta 13).
\end{abstract}

“(..) leyendo las cartas de los padres que andan en Japon me inflamo el coraçon con un gran deseo, de ir a gastar la poca vida que Nuestro Señor me diesse entre aquellos Padres." (Luis Ferrer, 1585, carta 47).

Com efeito, os relatos das experiências vivenciadas pelos missionários nem sempre se referiam a aspetos positivos e adequados para motivar os candidatos. Pelo contrário, descreviam de modo franco as grandes dificuldades que encontravam: as viagens na época ainda acarretavam inúmeros perigos; a experiência missionária era uma aventura constante desde a saída da terra natal e não diminuía quando chegavam. O trabalho nas colônias era árduo e a maioria dos religiosos se encontrava em condições precárias, com poucos recursos, somando-se ainda os empecilhos existentes também na convivência com os nativos das regiões. Desta maneira, além de "capacidade espiritual” para suportar tal experiência, era necessário que os jesuítas também tivessem força física e saúde, qualidades estas que são atestadas pelos candidatos redatores das cartas Indipetae:

"Terme edad de 20 o 21 años despues de cinco, que ha que entre en la Compañia, de buenas fuerças, y salud" (Balthasar de Torres, 1584, carta 13).

Não apenas as declarações de possuir uma boa força física, mas a admissão de fraquezas e medos, demonstram que os relatos colocam a vivência 
de seus autores além de simplesmente seguir as regras e as características desejadas pela Companhia.

\section{Pelas margens das Indipetae}

A Companhia de Jesus nasce em ambiente cultural fértil em novas experiências, marcado pelas Grandes Navegações, descobertas dos Novos Mundos e pelo espírito Humanista, passando ainda pela influência do movimento da Reforma Protestante e da Contra-Reforma Católica. Nesse contexto, Inácio de Loyola afirma que os claustros dos mosteiros não mais bastavam, pois era preciso que os religiosos confirmassem sua vocação através da experiência missionária e para que atingissem a salvação da sua alma assim como a dos próximos, era necessário lançar-se ao mundo:

"San Ignacio quiere que el ejercitante" se adentre en el corazón de la historia, no como espectador externo a ella sino como receptor y actor de la misma” (Fernandez-Martos,1991, p. 256).

Para elucidar tal idéia, Sto. Inácio não se baseou somente em suas leituras; sua biografia mostra que a origem da Companhia de Jesus está intimamente ligada à sua própria experiência de vida ${ }^{12}$ (Lacouture, 1994), já que o percurso de sua vida foi decisivo para a criação da Companhia de Jesus, assim como para a definição das características que eram exigidas dos jovens jesuítas para servirem nas Missões: desprendimento interior de todos os desejos terrenos, domínio das paixões e dedicação inflamada a Deus, além de saúde física, talento, firmeza de caráter e pureza de costumes. Enfim, armados física, intelectual e moralmente, poderiam se lançar ao mundo (Sepp, 1980). Nos Exercícios Espirituais há a descrição de um caminho para a mais sincera incorporação do sujeito à realidade, exercitando seu espírito de

\footnotetext{
${ }^{11}$ Este termo é característico dos leitores e praticantes da obra Exercícios Espirituais.

${ }^{12}$ Quando jovem, Inácio de Loyola era cavaleiro, mas foi ferido em uma das batalhas, o que o impossibilitou de continuar combatendo. Em repouso, começou a ler para passar o tempo; a biblioteca de sua casa era formada apenas por literatura sacra, permitindo que ele entrasse em contato com a temática religiosa; através da leitura das biografias de santos, percebeu que não conseguia apreender o sentido do que aqueles homens haviam vivido sem experienciar o conteúdo. Assim, Loyola andou pela Europa como peregrino e longe de sua condição de nobre, foi descobrindo, ao longo do caminho, quais eram as atitudes que afirmavam sua fé e o norteavam para buscar a salvação de sua alma (Lacouture, 1994).
}

maneira a vivenciar a amplitude de sua fé pois, para ele, é através da ação que o sentido religioso da experiência humana se realiza de forma verdadeira e plena. E este profundo senso de apego à realidade para que o ser humano não se perca em suas ilusões, leva em conta a idéia aristotélico-tomista da ação voltada a um objetivo final, pois quando se incorpora um sentido último à vida, a ação é guiada numa direção tal que possibilita o reconhecimento do desejo como autêntico, o que realiza e satisfaz (FernandezMartos, 1991). Voltando-se a este objetivo, a ação passa a ter um motivo e sentido, nela está a busca e a esperança do bem final. Aristóteles (1987) ${ }^{13}$, em Ética a Nicômaco, discorre de forma clara a respeito do que seria o bem final:

“Toda arte e toda indagação, assim como todo
propósito, visam a algum bem; por isto foi dito
acertadamente que o bem é aquilo a que todas as
coisas visam, (...) a causa de tudo o que se faz, (...)
o mais alto de todos os bens a que pode levar a
ação" ( p.120).

Assim, chega-se à conclusão de que este bem universal seria a felicidade, que sozinha seria suficiente, tornando desnecessárias as demais virtudes; desta forma, a ação é plena quando visa à felicidade como bem final, devendo-se então, compreender quais os meios para alcançar tal objetivo. Apesar de a afrimação de que o homem procura a felicidade parecer óbvia, para Aristóteles como para Santo Inácio isto não é conquistado facilmente, pois há no ser humano uma incessante luta contra seus desejos (ou apetites), que muitas vezes não o guiam para o bem:

"É difícil lutar contra o desejo; ele consegue tudo o que quer, ainda que lhe custe a alma. No entanto, isso não demonstra algo que não seja passível de contestação e luta, pois até as coisas boas são melhores quando são difíceis" (Aristóteles,1987, p.141).

Para Santo Inácio, o bem final identifica-se com a “Glória de Deus”.Como comenta O’Malley (2002), "na base dos ideais e da prática dos jesuítas estavam certas suposições acerca de Deus e de como o universo era governado o ponto de vista da imediação

\footnotetext{
${ }^{13}$ Vale retomar a importância de Aristóteles na constituição da base filosófica da Companhia de Jesus, e principalmente o estudo da Ética a Nicômaco, uma das obras mais lida e discutida por pensadores do período abordado.
} 
íntima e do poder da presença de Deus no mundo e na alma humana" (p.134), a ponto de afirmar "o mundo é a nossa casa” (p.76), o que leva o jesuíta a assumir como objetivo de vida, "o procurar em todas as coisas a Deus nosso Senhor” (Loyola, 1997, p.112) e a imitação de Cristo, a saber o empenho em "aceitar e desejar com todas as forças tudo o que Cristo Senhor amou e abraçou"( p.62).

São estas considerações que permitem a leitura das Indipetae de modo a poder compreendê-las a partir das categorias filosóficas e "psicológicas", dotadas de sentidos intencionados e compartilhados na época. São documentos que permitem que se entre em contato com a subjetividade e particularidade dos relatos destes jovens. Um dos tópicos recorrentes é o da indiferença, termo que aparece na maior parte das cartas Indipetae. Ao longo da análise, percebese que esta é uma virtude basal na espiritualidade jesuítica, mas apesar da freqüência com que surge nas cartas, esta palavra não pode ser interpretada em termos de uma simples regra retórica, pois envolve um importante trabalho de reflexão sobre o desejo de servir.

"Por amor de Nuestro Señor si a V.P. le parece que sea luego mi ida en la flota, que agora se partira al Piru, para esto, y para todo lo demas que V.P. me mandare estoi indifferente, y aparejado para cumplir exactamente la voluntad de V.P. y contanto Nuestro Señor esteja." (Blaz Maldonado, 1584, carta 11).

Para a Companhia, é importante que o candidato se posicione na condição de indiferença, por se tratar de uma atitude fundamental para progredir na vida espiritual. Neste sentido, a reflexão sobre a idéia de indiferença é central no momento de decisão e deliberação acerca do desejo de servir, relacionandose com outras questões referentes ao processo de auto-conhecimento realizado pelo jesuíta.

\section{O Desejo na Indiferença}

Para os redatores das cartas Indipetae, a experiência de decidir pelo além-mar relaciona-se ao reconhecimento do sentido e finalidade de suas próprias vidas. Kinerk (1984), ao comentar a espiritualidade jesuítica e o processo de eleição, assinala que quando se reflete sobre o que se quer, entra-se em contato com quem realmente se é. O autor acrescenta que a Com- panhia enfatiza o desejo pelo fato de este ser capaz de revelar o coração do homem. Santo Inácio valoriza e reconhece a força do desejo no afeto ${ }^{14}$, pedindo aos candidatos da Companhia, que se disponham a obedecer ao espírito da Instituição - encarnado em seus superiores -, que por sua vez, pode ajudá-los a conseguir seu fim último. Para a espiritualidade jesuítica, é este fim último que está em jogo nas decisões existenciais da vida. A importância dada à intenção das opções deve anteceder qualquer ação, mas se pode enganar quanto à intencionalidade, se os afetos estiverem desordenados, e desta maneira escolher o que não é para o próprio bem: Neste sentido, a indiferença representa, na espiritualidade jesuítica, a afirmação de que a decisão e as atitudes estão voltadas ao fim último pois, independente delas, qualquer escolha será para o bem do sujeito se houver a intenção clara para o bem final.

Desta maneira, percebe-se que os missionários dão significativo espaço nas cartas às justificativas do seu desejo de servir, como se vê no trecho da Indipetae a seguir:

\begin{abstract}
“ casi constrañido a lo pedir a V.P. no lo he hecho hasta agora por dos causas. La primera por parecerme ser negocio que se debia pensar mucho y tambiem encomendar deveras a Nuestro Señor. Lo qual e hecho eneste tiempo con todo el cuidado posible y siempre quanto mas enello pienso tanto mas parece mostrar Nuestro Señor hirme enesto gran parte de mi salvation, sino toda." (sem assinatura, 1584, carta 22).
\end{abstract}

Deve-se acrescentar que tanto para Santo Inácio, quanto para a tradição da filosofia aristotélicotomista, a deliberação sobre o desejo é acertada se ocorre pelo uso da razão; pois o intelecto é capaz de discernir e indicar a aplicação correta dos afetos.

\section{A Indiferença e a Obediência}

Iparraguirre (1964) chama a atenção para a época em que estes jovens escrevem, pois se trata de um período marcado pelos ideais do Renascimento, especialmente por uma busca da ordem e da regra em tudo. Como se pode perceber, a experiência jesuítica era fortemente marcada pela obediência aos superiores e às regras da Companhia, sendo necessário que o

\footnotetext{
14 Dominguez (1992) acrescenta que para Santo Inácio este reconhecimento se dá através da experiência e do sentir, não é um conhecimento meramente intelectual.
} 
jovem missionário se entregasse à Companhia disposto a mortificar e ordenar os afetos ${ }^{15}$ para o serviço a Deus como centro e sentido de sua existência.

O que movia estes jovens a aceitarem estas obrigações?

Para eles, a obediência também é uma virtude a ser alcançada:

" $Y$ despues de entrado en la Compañia ha estado tam herido desto mi coraçon que me a dado en que entender en mortificarle para alcançar la perfecta indifferencia.” (Myn de Gurpegui, carta 28).

Seguindo os caminhos indicados por Deus ${ }^{16} \mathrm{e}$ os ensinamentos de seus superiores, evitam-se assim "erros do próprio juízo e defeitos e pecados da própria vontade” (Loyola,1993, p.58). Neste sentido a obediência não é entendida como falta de liberdade, pois parte da confiança de que, obedecendo a tais regras, o jovem estaria seguindo passos de pessoas que sabem como atingir a realização do seu desejo de salvação das almas (Massimi \& Prudente, 2002), assim, posicionando-se como indiferentes ao desconforto das obrigações, pois o que norteia e compensa o sofrimento é a busca deste fim.

Para isso, o jesuíta deve se colocar em posição de indiferença frente aos afetos, o que possibilita obedecer com liberdade, pois não há sofrimento quando há a mortificação e desapego de objetos que reconhecidamente poderiam desnortear a busca pelo bem final. Iparraguirre (1964) assinala que os jesuítas não se sentiam escravos de nenhuma regra ou costume, apenas se punham como indiferentes a tudo isto:

"Si aquellos autores insisten en la mortificación y en la purificación afectiva, no es porque desean matar el amor, sino porque quieren aprovechar su essencia y fuerza del modo más puro y perfecto.” (p.32).

A obediência relaciona-se ainda à idéia de desprendimento, que consiste no desapego de todo o egoísmo e na mortificação das paixões, característica moral desejada pela Companhia e que denota a total disponibilidade desses jovens candidatos a missionário. Uma obediência que pode ser vivida sem sofri-

\footnotetext{
${ }^{15}$ Dominguez (1992) acrescenta que para Santo Inácio este reconhecimento se dá através da experiência e do sentir, não é um conhecimento meramente intelectual.

16 "Jo há 7 o 8 anos deseo yr a las Indias indiferentemente a las que me quisiere embiar el Senõr (...)y assi me atrevo a pedir lo confiado que se ordenara conforme a mayor gloria de Dios” (Juan Sirvent, 1584).
}

mento pelo desapego material, porque o mais seguro estaria dentro de si: a crença no bem final.

Para S. Tomás de Aquino (1980), o bem final é a causa primária de todas as coisas. Deve-se procurar o melhor meio de atingi-lo, no entanto a ligação aos meios, geraria apego às causas secundárias, que proporcionam apenas satisfação imediata, podendo confundir. Assim, a busca pela causa primária e a devoção fervorosa a Deus fazem com que qualquer sacrifício seja válido para o fim último da salvação da alma.

\section{A Indiferença que me preenche de Coragem}

“El Señor me da grandisimos deseos de verme
enpleado en su serbicio mas particularmente de lo
que hasta quanto lo hecho y esto no es sin fundamen-
to sino muy conforme a mi bocacion pues la princi-
pal causa que me mobio a entrar en la Compañia fue
que oyendo decir que los de la Compañia yban y se
ponian entre ynfieles en grandes peligros de sus bidas
por salbales a ellos las animas”. (Seraphin
Bonaventura Coçar, 1586, carta 4).

São Tomás de Aquino (1980) cita Aristóteles em sua Suma Teológica, colocando que "os que têm esperança firme são corajosos", e acrescenta "a causa da coragem está em trazer na fantasia, a esperança da salvação. (...) os de mais confiança em Deus, são mais corajosos” (p.1353). Ou seja, quando o desejo é autêntico e firmado na esperança do "fim último", a vontade de realizá-lo supera o medo. Esta afirmação esclarece a posição dos jesuítas que persistiam no seu desejo a ponto de se declararem indiferentes quanto à escolha do lugar para onde poderiam ser enviados, confiando assim na esperança firme de realização, o que motivava a coragem de se lançarem ao desconhecido.

Contudo percebe-se, no decorrer da leitura e análise das cartas, que os autores que escreviam a Indipetae pela primeira vez, dificilmente se colocavam de todo indiferentes, indicando o lugar para o qual gostariam de ser enviados e as razões da escolha. A palavra "indiferença" surgia em seu texto quase como uma norma a seguir em obediência às intenções da Companhia. Por outro lado, quando escrevia a Indipetae, tendo sido denegado o pedido anterior, aumentava no seu texto a insistência na palavra indiferença: os que persistiam no pedido, ou estavam há mais tempo na Companhia, punham-se inteiramente 
indiferentes e não faziam mais referência aos lugares que seriam de seu maior agrado, o que faz pensar na persistência da vontade de realização do desejo de ser missinário superando a afeição, ou o medo por este ou aquele lugar.

Desse modo, a idéia de indiferença pode ser entendida, neste contexto, como manifestação de coragem, sendo que o desejo de servir era superior ao medo do inusitado. A fé de que existe um bem final que compensa a mortificação dos afetos é, para S. Tomás de Aquino, o que dá coragem de ser indiferente, ou seja, é o que põe o homem acima do medo, da vaidade. São as ações fundadas na esperança do bem final que fazem com que ele não se perca nas paixões ou se contente só com satisfações imediatas.

Santo Inácio segue este raciocínio considerando que o jesuíta que não é mortificado tem medos. Acrescenta que se ele quiser participar do serviço apostólico e tiver medo do mar, por exemplo, vive uma condição paralisante (Kinerk, 1984). Por isso a importância de disciplinar o desejo e colocar-se indiferente quanto a estes afetos.

\section{Indiferente Equilíbrio}

Para Aristóteles (1987), esta busca por satisfação total e indiferença quanto às imediatas, exige controle da razão sobre as emoções, ou seja, quando as paixões são regradas pelo intelecto, encontra-se a virtude moral a ser atingida por todas as disposições da alma: o meio-termo, ao qual as ações devem visar. Pois através da moderação, realiza-se a justiça, e a partir daí, entende-se o equilíbrio necessário para a vida interior, que deve ser visto como articulação dinâmica de três funções principais: o entendimento, a vontade e os afetos. O crescimento espiritual dar-se-ia através da busca deste equilíbrio, evitando excessos, ordenando e regrando o corpo físico e psíquico ${ }^{17}$. Ou seja, caso estivesse servindo ao seu desejo, quaisquer vicissitudes seriam suportáveis, ao mesmo tempo em que as atitudes seriam moderadas e caminhariam para o sentido de seu bem final. Pelo contrário, se a escolha de servir não fosse um desejo sincero, o indivíduo não iria se sujeitar a se por como indiferente, pois esta posição exige coragem, desprendimento e sacrifício dos afetos; e, face ao desejo autêntico, os meios para se atin-

\footnotetext{
${ }^{17}$ Como visto, Sto. Inácio coloca a indiferença como um estado de disposição necessária para a ordenação interior dos afetos.
}

gir o bem final são indiferentes, e o que deve mover a ação é o bem final, não as causas secundárias.

Nesse sentido, fica clara a razão das regras exigidas pela Ordem, por vezes difíceis de serem compreendidas, a exemplo da obediência ao superior, a humildade, e o desprendimento. Com efeito, a mortificação é relativa aos afetos - causas secundárias para a satisfação da vida - mas quando colocado indiferente a estes, o jesuíta aceita a mortificação, pois se coloca em total disponibilidade. Desta maneira, atinge a virtude de se distanciar dos seus próprios afetos de modo que possa reconhecer o sentido de sua ação, e deliberar sobre o desejo através do meio-termo:

“Devo ter bem presente o fim para que fui criado, a
saber: louvar a Deus nosso senhor e salvar a minha
alma. Devo além disso permanecer numa inteira
indiferença, sem nenhuma afeição desordenada, de
forma que não esteja mais inclinado ou afeiçoado a
escolher o objeto proposto do que a deixá-lo, ou
mais a deixá-lo do que escolhê-lo, achando-me em
equilíbrio, como o fiel de uma balança, a fim de
seguir aquilo que sentir ser para a maior glória e
louvor de Deus nosso Senhor e salvação de minha
alma” (Loyola,1996, p. 101). Indiferente para me sentir Livre

Como se pode ver, a virtude da indiferença é ponto central na espiritualidade jesuítica, pois possibilita que a escolha seja livre. Trata-se da liberdade conquistada pela ordenação dos afetos. No entanto, é importante frisar que não se indica renunciar aos afetos, ou algo semelhante, mas sim, sentir-se livre frente a eles ${ }^{18}$. Não se precisa optar por querer mais uma coisa do que por deixá-la, nem deixá-la mais do que tê-la: a liberdade está na conquista da virtude do meio-termo. Não se trata de não amar, mas de não amar em excesso ou deficientemente, sendo este o caminho indicado para conseguir a liberação espiritual das ataduras das paixões que vinculam o ser humano à Terra (Iparraguirre, 1964). Nesta perspecti-

\footnotetext{
18 "Por todo ello, creemos importante insistir en que la afectividad no es nunca considerada por Ignacio como objeto de negación, anulación o minusvaloración, como tantas veces se ha tenido la tentación de considerar dentro de la espiritualidad cristiana y jesuítica en particular. No se trata de eliminar el afecto a las criaturas, para moverse según lo que vendría a ser un racionalismo extremo o una forma larvada de estoicismo. Se trata de que ese amor que a la cosa se tiene sea ordenado.(...) Se trata de afectivizar al máximo las ideas y representaciones: meditar para abrazar." (Domínguez, 1991, p.113-114).
} 
va, o homem purificado pela força divina é liberado de seus impulsos cegos, devendo olhar para dentro de si para ter conhecimento de seu desejo:

\section{"No existe esse fundamentalismo, em el que la Idea se impone como absoluto sobre el hombre para dejarle paralizado. Hay que hacer discernimiento, averiguación de lo que quiero hacer com mi vida" (Domínguez,1991, p.117).}

Como visto e analisado, a disposição de se candidatar às Índias exigia coragem, pois os jovens se colocavam a mercê de um além-mar desconhecido e por isso, assustador. Em contrapartida, a curiosidade diante do mistério do Novo Mundo e o desejo de salvação superavam o medo do ignoto. Para tanto, era necessário que eles realmente acreditassem na supremacia de seu desejo e é neste sentido que se entende o caráter libertário da ação, ainda que na presença de questões como a obediência e a humildade. Os documentos analisados evidenciam que através de um processo de auto-conhecimento, admitindo e ordenando as afeições, de maneira a deliberar para maior realização pessoal, buscava-se o sentido de ser livre para que a vida pudesse ser vivida de forma plena e o equilíbrio não fosse mais um ponto de luta, mas de satisfação.

“(...)para la mayor gloria Divina, e bien de mi alma, e ayuda delos proximos, la qual mission es para el Brasil.(...)Contudo indiferente para qual quier por la qual rason pido a Vuestra Partenidade, siendo servido, me conceda el despacho de mi peticion, contanto que en todo haga lo que fuere de mayor gloria Divina." (Alonso Pestana, 1692).

\section{A Indiferença como Diferenciação: vendo possibilidades}

Esse caminho especulativo sobre um recorte da experiência jesuítica nos séculos XVI e XVII leva a reflexões que questionam e interpelam a atualidade, ainda que se tenha plena consciência de que o presente é norteado por visões de homem e mundo muito distantes da modalidade antropológica proposta pelos jesuítas do século XVI e XVII, e que se elucide a importância de situar o lugar social e histórico, "é necessário lembrar que a leitura do passado, por mais controlada que seja pela análise dos documentos, é sempre dirigida por uma leitura do presente" (De Certeau,2002, p.34).
Se se analisar a doutrina jesuítica como manifestação de uma realidade social que se expressa em atos e práticas, é evidente que os documentos escritos pelos jovens jesuítas de que se fala e os textos teóricos utilizados para melhor compreensão dessas vivências, mostram que se trata aqui de uma visão de mundo peculiar.

Em que sentido ela interpela aos homens da pós-modernidade?

A análise do passado pode iluminar o presente pelo conhecimento do que constrói o presente, mas também, essas experiências enfatizam perguntas sobre a própria vivência humana e evidenciam possibilidades de vida, convidando a um diálogo consigo mesmo, necessário em momentos de decisão. É evidente o contraste e a distância entre os critérios ideais que norteavam as decisões no modus vivendi dos jesuítas e a importância dada hoje à busca de satisfação do desejo por objetos materiais. Discute-se o fato de o homem tentar substituir uma falta, por produtos que lhe sugerem uma suposta felicidade, incentivada pelo consumismo, que camufla a real necessidade das pessoas, em favor da lei do mercado. Contrariamente, o que as cartas mostram é que a indiferença vivenciada pelos jovens jesuítas propõe uma análise da intenção do desejo que satisfaça o ser, estimula o auto-conhecimento para que o homem não se perca, na busca da felicidade, por caminhos ilusórios. Neste sentido, este trabalho propõe olhar para o passado de modo que possibilite uma reflexão crítica acerca do presente, tomando certa distância do que se vive, para poder olhar a própria experiência com olhos menos ingênuos.

Reinterpretando em chave atual o conceito jesuítico de indiferença, Fernandez-Martos (1991) define-a como a distância necessária para uma suprema proximidade, pois sem ela não emerge o símbolo e o sentido. Para alcançar a indiferença é necessário um amadurecimento, "Crecer es dolerse em uma diferenciación creciente.” (p.246). A criança para ele, não é capaz de fazê-lo, pois não tem ainda um mundo simbólico interiorizado e necessita, por exemplo, de objetos transicionais que representem o objeto ausente externamente. $\mathrm{O}$ autor conclui que muitas das afeições desordenadas são como crianças pequenas que tentam compensar materialmente outras ausências e para deixar essa condição que 
paralisa a realização pessoal, é necessária a indiferença. Quando se afasta de si mesmo, ou do próprio tempo, dá-se espaço para que outras possibilidades surjam, facilitando assim, que se aceite o diferente, que se acolha também a alteridade, o outro em sua semelhança e diferença.

\section{Referências Bibliográficas}

Aristóteles, (1987). Ética a Nicômaco. São Paulo: Nova Cultural.

Aquino, Tomás de (1980). Suma Teológica vol.III. Est. Sulina. UCS.

Andrade, A. A. B. (1981). Contributos para a história da mentalidade pedagógica portuguesa. Lisboa: Imprensa Nacional-Casa da Moeda.

Baldini, U. (1992). Leges impone subactis. Studi su Filosofia e Scienza dei Gesuiti in Italia. 15321632. Roma: Bulzoni.

Barreira, C. R. A. \& Massimi, M. (2002). A Moralidade e a Atitude Mental no karate-do no Pensamento de Gichin Funakoshi. Memorandum, 2, 3954. World Wide Web: http://www.fafich.ufmg.

Barreto, L. F. (1983). Descobrimentos e Renascimento. Formas de Pensar e de Ser nos séculos XV e XVI. Lisboa: Imprensa Nacional-Casa da Moeda.

Caeiro, F.G. (1982). O pensamento filosófico do século XVI ao século XVIII em Portugal e no Brasil, Acta do 1 Congresso Luso-Brasileiro de Filosofia, p.51-90.

Caeiro, F. G. (1989). El problema de las raíces históricas. Em E. M. Barba e cols., Iberoamerica, una comunidad (p.377-389). Madrid: Ediciones de Cultura Hispánica.

De Certeau, M. (2002). A Escrita da História. Rio de Janeiro: Forense Universitária.

Domínguez, L. (1991). Que Són Las Afeciones Desordenadas. Em C. Alemany \& J. Monge-Garcia (Orgs.), Psicologia y Ejercicios Ignacianos La Transformacion del Yo en la Experiencia de Ejercicios Espirituales (pp.95-107). Bilbao: Mensajero.

Domínguez, S. J. (1992). Las "Afeciones Desordenadas": Infllujo del subconsciente en la vida espiritual. Bilbao: Mensajero.
Fernandez-Martos, J. M. (1991). La Incorporacion de La Realidad. Em C. Alemany \& J. Monge-Garcia, (Orgs.), Psicologia y Ejercicios Ignacianos: La Transformacion del Yo en la Experiencia de Ejercicios Espirituales Vol.1 (pp.241-276). Bilbao: Mensajero.

Giard, L. (1995). Les jésuites á la Renaissance. Système éducatif et production du savoir, Paris: Presses Universitaires de France.

Giard, L. \& Vaucelles, L. (1996). Les jésuites à l'âge baroque, 1540-1640, Grenoble: Presses Universitaires de France.

Iparraguirre, I.S.I. (1964). Estilo Espiritual Jesuitico, 1560 - 1600. Bilbao: El Mensajero.

Kinerk, E. E. (1984). Studies in the Spirituality of Jesuits- Eliciting Great Desires: Their Place of the Society of Jesus. American Assistancy Seminar on the Jesuit Spirituality, Vol XVI. St. Louis: SAGE.

Lacouture, J. (1994), Os Jesuítas; 1. Os Conquistadores, Tradução: Ana Maria Capovilla, Rio de Janeiro: L \& PM editores.

Longo, N. (1981). De epistola condenda: Lárte di "componer lettere" nel Cinquecento. Em A. Quondam, (Org.), Le "carte messagiere": retorica e modelli di comunicazione epistolare: per un indice dei libri di lettere del Cinquecento (pp.178198). Roma: Bulzoni Editore.

Loyola, I. (1993). Cartas de Santo Inácio de Loyola. São Paulo: Edições Loyola.

Loyola, I. (1996). Exercícios Espirituais. São Paulo: Edições Loyola.

Loyola, I. (1997). Constituições da Companhia de Jesus e normas complementares. (Orignal, 1558) São Paulo: Edições Loyola.

Maravall, J. A (1997). A cultura do Barroco. São Paulo: EDUSP.

Martins, A. M. (1989). Conimbricenses, Logos, 2, 1112-1126.

Massimi, M. (1999). A “Psicologia” dos Jesuítas: Uma Contribuição à História das Idéias Psicológicas. Em Psicologia, Reflexão e Crítica, 14 (3), p. 625-633. 
Massimi, M. \& Prudente, A. B. (2002). Um incendido desejo das Índias..., São Paulo: Loyola. Coleção CES.

O’ Malley, J. W. (1993). Religious Culture In the Sixteenth Century, Preaching, Retoric, Spirituality and Reform, Mariorum. Vermont: Asgate Publishing.

O’ Malley, J. W. (1999). 1 primi gesuiti. Milão: Vita e Pensiero.

O’Malley, J. W. (2002). Os primeiros jesuítas. Edição brasileira e tradição de D. A. Donida. Baurú: Edusc.

Pecora, A. (1999). Cartas à Segunda Escolástica. Em A. Novaes, (Org.), A outra margem do Ocidente, (pp.373-416) São Paulo: Funarte-Companhia das Letras.

Rodrigues, M. A. (1985). Do Humanismo à ContraReforma em Portugal, Revista de História das Idéias, v.10, p. 40-52.

Roscioni, G. C. (2001). Il desiderio delle Indie. Storie, sogni e fughe di giovani gesuiti italiani. Torino: Einaudi.

Sepp, Padre Antônio (1980). Viagem às Missões Jesuíticas e Trabalhos Apostólicos. São Paulo: EDUSP. 